\title{
A cross sectional study on the motivators for Asian women to attend opportunistic mammography screening in a private hospital in Malaysia: the MyMammo study
}

Norhashimah Hassan ${ }^{1,2}$, Weang Kee Ho ${ }^{3}$, Shivaani Mariapun ${ }^{1,2}$ and Soo Hwang Teo ${ }^{1,2^{*}}$

\begin{abstract}
Background: To date, because of limited budgets and lower incidence of breast cancer, the majority of Asian countries do not have population-based screening programmes, but instead offer opportunistic screening. However, there have been few studies which have assessed the motivators for women attending such programmes and the appropriateness of the programmes in terms of targeting women at risk.

Methods: We conducted a prospective cross-sectional study of 1,619 women aged 40 to 74 years attending a subsidized opportunistic screening mammogram from October 2011 to October 2013 at a private hospital in Malaysia. Breast cancer risk was estimated using the Gail Model and two-step cluster analysis was used to examine the motivators of attending screening.

Results: Although Malaysia comprises $54.5 \%$ Malay, $24.5 \%$ Chinese and $7.3 \%$ Indian, the majority of women in the MyMammo Study were Chinese (70.1\%) and $99.2 \%$ had a $<2 \%$ ten-year risk of breast cancer. The most commonly cited barriers were the perception of not being at risk and fear of painful mammography. We found that highly educated women, cited doctors, family and friends as their main motivators. Of those with only secondary school education, their main motivators were doctors.

Conclusions: Taken together, our results suggest the women attending opportunistic mammography screening in Asia are at low risk of breast cancer and this poses challenges to cost-effective and equitable strategies for cancer control. We propose that to improve uptake of screening mammography, awareness programmes should target both doctors and members of the public.
\end{abstract}

Keywords: Mammography, Screening, Breast Cancer, Malaysia, Asia

\section{Background}

Breast cancer is the most common cancer in women and accounts for $\sim 12.7 \%$ of all cancer deaths in Asian women [1]. Although breast cancer incidence is lower in Asia compared to that in Western countries, it is now rising rapidly in Asian countries because of longer life expectancy and dramatic changes in parity and lifestyle

\footnotetext{
* Correspondence: Soohwang.teo@carif.com.my

${ }^{1}$ Cancer Research Initiatives Foundation, Sime Darby Medical Centre, 1 Jalan SS12/1A, Subang Jaya 47500, Selangor, Malaysia

${ }^{2}$ Breast Cancer Research Unit, University Malaya Cancer Research Institute, Faculty of Medicine, University Malaya Medical Centre, University Malaya, 50603 Kuala Lumpur, Malaysia

Full list of author information is available at the end of the article
}

[1-4]. The increasing burden of breast cancer in Asian countries is exacerbated by late presentation and limited access to therapies, resulting in poorer outcomes [5-7].

In high-income Asian countries with higher breast cancer incidence, such as Singapore, Korea and Japan, organized national mammographic screening is available, but uptake varies from 20 to $57 \%$ [8-12]. In the other Asian countries, only opportunistic screening is available [13] and uptake is generally low, ranging from $<1 \%$ in Thailand [14], to $\sim 7 \%$ among rural Malaysian women [15-17]. A number of reasons for poor uptake have been described in Singapore, Thailand, Malaysia and Iran, and 
these include cost of screening, lack of time, distance to screening facilities and fear of cancer [14, 18-20].

Faced with limited budgets and an increasing incidence of breast cancer, the governments of Asian countries are facing difficult decisions on how to offer screening equitably and cost-effectively, and in particular, how to target limited resources to women at higher risk of developing breast cancer. However, there is paucity of data on the risk profile of Asian women attending opportunistic screening and limited data on how to motivate women to come forward for screening. In this study, we sought to describe the risk profile of women attending opportunistic screening at a private hospital in Malaysia, to examine the barriers and motivators of women attending screening, and to explore whether there are subgroups of healthy women with similar selfreported motivators for attending screening in Malaysia. Findings from these analyses may inform the utility of opportunistic mammography screening and further, the functional clustering may provide insight into how screening messages should be framed for more effective promotion of screening mammography in the future.

\section{Methods}

\section{Study description}

The Malaysian Mammography Study [MyMammo] is a subsidized opportunistic mammogram screening programme in a private tertiary hospital located in a suburban area in Malaysia. Screening was offered to women who did not have a personal history of breast cancer and who have not had a mammogram for at least one year prior to participating in the programme. Participants were recruited using flyers and posters at the hospital, and articles in the mainstream English, Chinese and Malay media. From October 2011 to October 2013, 1,619 women were enrolled into the study. Participants had a digital mammogram, donated a blood sample for research and completed a questionnaire of information in relation to demographic characteristics, anthropometric factors, menstrual and reproductive history, family history of cancer and, motivators and barriers for participating in the MyMammo study. Women were excluded if they were younger than 40 years old $(n=6)$, older than 74 years old $(n=4)$, previously diagnosed with other cancer $(n=23)$ or symptomatic $(\mathrm{n}=133)$, leaving 1,453 in the final analysis. All women provided informed consent and this study was approved by the Sime Darby Medical Centre Independent Ethics Committee.

\section{Estimation of breast cancer risk}

The ten-year risk of breast cancer in all women were calculated at age of participation in MyMammo study using the publicly available Gail Model by including the following variables: age at menarche $(<12$ years, $12-13$ years, $\geq 14$ years), age at first live birth $(<20$ years, 20 - 24 years, 25-29 years, $\geq 30$ years), history of previous breast surgery and the number of first degree relatives affected with breast cancer. Subjects were categorized as parous if they have had at least one full term pregnancy (live or still births) and the family history of breast cancer in a first degree relative included affected mothers and sisters. For calculations of population risk to breast cancer, the population risk of the Malaysian Chinese was based on that of the Chinese Asian-Americans while the population risk of Malaysian Malay and Indian women was based on that of other Asian-Americans [21].

\section{Statistical analysis}

SPSS software [Version 21] was used for all data analysis. The association between mammography history and baseline characteristics was investigated using Student's $t$ test and chi-square test for continuous and categorical variables respectively. A two-step cluster analysis was used to identify sub-groups of women with similar self-reported motivators for participating in the MyMammo Study. Women with previous breast biopsy $(n=136)$ were excluded, leaving a total of 1,317 women for analysis. Initial analysis included all variables and thereafter, variables without significant association with mammography history were removed sequentially (starting with the least significant variables). Models with acceptable cluster quality, smallest Schwarz's Bayesian Criterion and significant differences between socio-demographic variables and motivators were selected. Differences between clusters were determined by Kruskal-wallis test for continuous variables and chi-square test for categorical variables.

\section{Results}

\section{Study cohort}

The MyMammo study is an opportunistic mammography screening programme established at a private hospital in the suburban area of Subang Jaya in Malaysia. The mean age was 50 years old, the majority of participants were Chinese [70.1\%], >90 \% had secondary or tertiary education and $19 \%$ were considered high income. The mean age of menarche was 13 years old and $84 \%$ of women were parous, with a mean age of first live birth of 28 years old. Whilst $30 \%$ of women had ever used oral contraceptives, less than $10 \%$ had used hormone replacement therapy. Only $10 \%$ of women report a family history of breast cancer and $9 \%$ had previously had a breast biopsy. Twenty one percent of patients had previously had gynaecological surgery. Overall, the mean ten-year risk for women aged $40-79$ was $0.77 \%$, ranging from $0.4 \%$ to $14.4 \%$. The majority of women ( $\mathrm{n}=1453,99.2 \%)$ were estimated to have a $<2 \%$ risk of breast cancer, with only $0.8 \%(\mathrm{n}=19)$ at $2 \%$ risk (Fig. 1). 


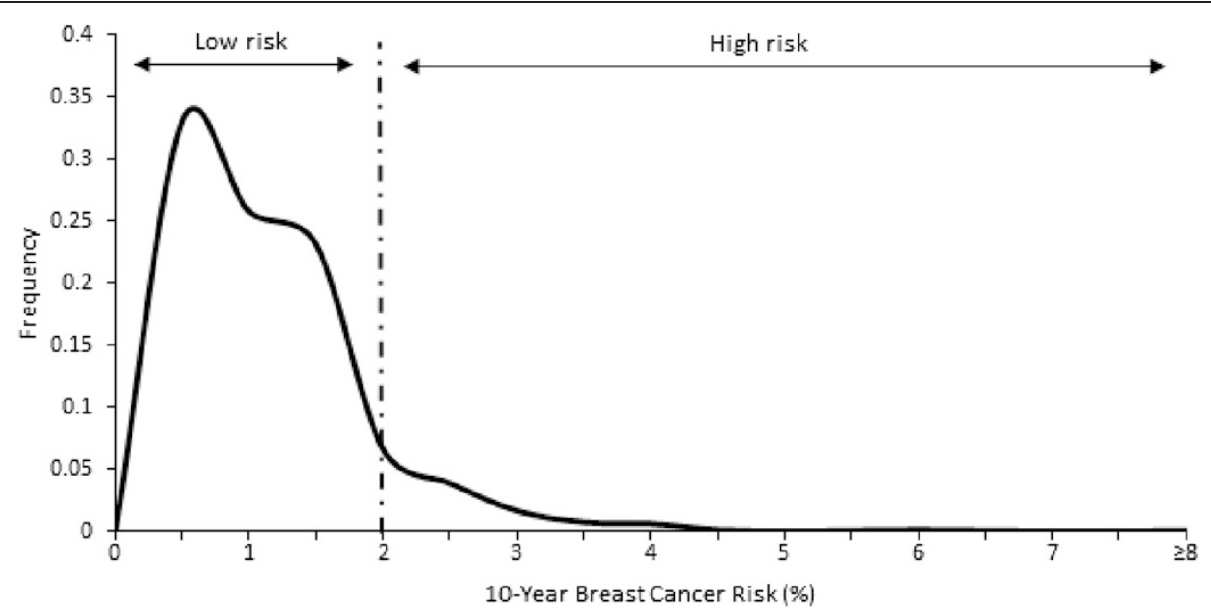

Fig. 1 Distribution for ten-year risk invasive breast cancer in participants of the MyMammo study. Low risk is defined by having 10-year risk of less than $2 \%$ while high risk is defined by $2 \%$ or greater risk of developing breast cancer in the next 10 years. The majority of women ( $n=1415,97.3 \%)$ were at low risk of breast cancer and 38 out of 1453 of women (2.7 \%) is predicted to be at risk of developing invasive breast cancer in the next 10 years

Women with previous mammogram were older $(p<$ 0.001 ), tend to have higher socio-economic status (income $p=0.01$, educational level $p=0.006$ ), more likely to be menopausal $(p<0.001)$, have first live birth at an older age $(p=0.001)$, and more likely to have had hormone replacement therapy $(p<0.001)$ compared to women without previous mammogram. They also have higher proportion of positive family history of breast cancer $(p<0.001)$ and diabetic $(p=0.05)$. The remaining variables, namely ethnicity, age at menarche, smoking status and previous breast or gynaecological surgery, did not differ significantly between the two groups (Table 1).

For 709 women (48.8\%) that cited the MyMammo Study as their first breast screening mammogram, $30 \%$ (209) cited perception that they are not at risk, $20 \%$ (139) cited fear of painful mammography, and $10 \%$ (68) cited cost, as barriers of attending opportunistic screening.

\section{Cluster analysis}

Whilst the association analyses revealed the differences between women who have previously attended mammogram compared with those who had not, it did not reveal whether there were subgroups of healthy women with similar self-reported motivators for attending opportunistic screening in Malaysia. To do this, we conducted a cluster analysis to determine the characteristics of women presenting for opportunistic screening, starting first with a model containing all variables in Table 1, mammography history, age at first mammogram and motivators for attending screening, and sequentially excluding variables with the least association with mammography history (Table 2). We observed that the full model and Model two generated more than three clusters with poor separation. Models 1, 3, 4 and 6, and Models 5, 7 and 8 generated two and three clusters, respectively, with fair cluster quality and similar profiles. However, only the three-cluster models show a significant difference between motivators. Although there is a slight increase in BIC value after dropping parity and menopausal status from the analysis (comparing Model 5 with Model 8), the most parsimonious model was Model 8, as it contained the least variables and all variables in the model remained significantly different between the three clusters (Table 3).

The first and largest cluster $(\mathrm{N}=451)$ comprised older women (mean age 52 years), all of whom have had a mammogram previously (mean age of first mammogram 44 years). Notably, women in cluster 1 had the most significant family history of breast cancer (13.1\%) and the motivators for participating in opportunistic screening were varied (family and friends, doctors, themselves and public campaign).

Cluster 2 is the smallest group $(\mathrm{N}=262)$ and consists of younger participants (mean age 45 years), the majority of whom have never had a mammogram (98.5\%). They are the most highly educated (75\% have attended college or university) and have the highest monthly income (38 \% earned above RM10,000 per month). Women of this cluster had the smallest proportion of overweight (35.9\%) or diabetic women $(2.7 \%)$ and the lowest use of hormone replacement therapy $(2.7 \%)$. These women were motivated to attend opportunistic screening by their doctors, family or friends.

Cluster $3(\mathrm{~N}=276)$ consists of older women (mean age 51 years), the majority of whom have never had a mammogram previously $(93.8 \%)$. Women in this cluster had the lowest socio-economic status: $98.9 \%$ were educated at 
Table 1 Malaysian Mammographic Study cohort description by mammography history

\begin{tabular}{|c|c|c|c|c|c|c|c|}
\hline \multirow[t]{3}{*}{ Variable } & \multirow{2}{*}{\multicolumn{2}{|c|}{$\begin{array}{l}\text { All women } \\
N=1453\end{array}$}} & \multirow{2}{*}{\multicolumn{2}{|c|}{$\begin{array}{l}\text { Previous mammogram } \\
\mathrm{N}=744\end{array}$}} & \multirow{2}{*}{\multicolumn{2}{|c|}{$\begin{array}{l}\text { First mammogram } \\
\mathrm{N}=709\end{array}$}} & \multirow[t]{3}{*}{$P$ value } \\
\hline & & & & & & & \\
\hline & $N$ & $\%$ & $\mathrm{~N}$ & $\%$ & $N$ & $\%$ & \\
\hline \multicolumn{8}{|l|}{ Demographics } \\
\hline $\mathrm{Age}^{1 \mathrm{a}}[$ mean, sd $]$ & 50.0 & 7.0 & 53.0 & 7.0 & 48.0 & 7.0 & $<0.001$ \\
\hline \multicolumn{8}{|l|}{ Ethnicity ${ }^{2 a}$} \\
\hline Chinese & 1018 & 70.1 & 530 & 71.2 & 488 & 68.8 & 0.194 \\
\hline Indian & 223 & 15.4 & 117 & 15.7 & 106 & & \\
\hline Malay & 160 & & 69 & 9.3 & 91 & 12.8 & \\
\hline Others & 52 & 3.5 & 28 & 3.8 & 24 & 3.4 & \\
\hline \multicolumn{8}{|l|}{ Education Level $^{2}$} \\
\hline Primary & 90 & 6.2 & 34 & 4.6 & 56 & 8.1 & 0.006 \\
\hline Secondary & 728 & 50.1 & 366 & 49.9 & 362 & 52.3 & \\
\hline Tertiary & 608 & 41.8 & 334 & 45.5 & 274 & 39.6 & \\
\hline Missing & 27 & & 10 & & 17 & & \\
\hline \multicolumn{8}{|l|}{ Monthly Income (RM) ${ }^{2}$} \\
\hline Below 5 k & 689 & 47.4 & 325 & 44.1 & 364 & 52.1 & 0.010 \\
\hline $5 \mathrm{k}$ to $10 \mathrm{k}$ & 470 & 32.4 & 260 & 35.3 & 210 & & \\
\hline Above $10 \mathrm{k}$ & 277 & 19.1 & 152 & 20.6 & 125 & 17.9 & \\
\hline Missing & 20 & & 10 & & 10 & & \\
\hline \multicolumn{8}{|l|}{ Hormonal } \\
\hline \multicolumn{8}{|l|}{ Endogenous } \\
\hline Age at menarche ${ }^{1 a}[$ mean, sd] & 13.0 & 1.0 & 13.0 & 1.0 & 13.0 & 1.0 & 0.626 \\
\hline Missing & 10 & & 5 & & 5 & & \\
\hline \multicolumn{8}{|l|}{ Menopausal status ${ }^{2}$} \\
\hline Pre/perimenopausal & 783 & 53.9 & 299 & 40.2 & 484 & 68.6 & $<0.001$ \\
\hline Post-menopausal & 667 & 45.9 & 445 & 59.8 & 222 & 31.4 & \\
\hline Missing & 3 & & 0 & & 3 & & \\
\hline \multicolumn{8}{|l|}{ Parity $^{2}$} \\
\hline Nulliparous & 229 & 15.8 & 104 & & 125 & 17.6 & 0.057 \\
\hline Parous & 1224 & 84.2 & 640 & & 584 & 82.4 & \\
\hline Age at first live births ${ }^{1 \mathrm{a}}[$ mean, sd] & 28.0 & 5.0 & 28.0 & 5.0 & 27.0 & 5.0 & 0.001 \\
\hline Missing & 230 & & 105 & & 125 & & \\
\hline \multicolumn{8}{|l|}{ Exogenous } \\
\hline \multicolumn{8}{|l|}{ Oral contraceptive usage status ${ }^{2}$} \\
\hline Never & 1004 & 69.1 & 508 & 68.5 & 496 & 70.4 & 0.435 \\
\hline Ever used & 443 & 30.5 & 234 & 31.5 & 209 & 29.6 & \\
\hline Missing & 6 & & 2 & & 4 & & \\
\hline \multicolumn{8}{|l|}{ Hormone replacement therapy } \\
\hline \multicolumn{8}{|l|}{ (HRT) status ${ }^{2}$} \\
\hline Never & 1306 & 89.9 & 627 & 84.6 & 679 & & $<0.001$ \\
\hline Ever used & 142 & 9.8 & 114 & 15.4 & 28 & & \\
\hline Missing & 5 & & 3 & & 2 & & \\
\hline
\end{tabular}


Table 1 Malaysian Mammographic Study cohort description by mammography history (Continued)

\section{Medical history}

Family history of breast cancer ${ }^{2 a}$

\begin{tabular}{|c|c|c|c|c|c|c|c|}
\hline No & 1301 & 89.5 & 646 & 86.8 & 655 & 92.4 & $<0.001$ \\
\hline Yes & 152 & 10.5 & 98 & 13.2 & 54 & 7.6 & \\
\hline \multicolumn{8}{|l|}{ Previous breast biopsy status ${ }^{2 a}$} \\
\hline No & 1305 & 89.8 & 676 & 91.5 & 629 & 89.6 & \multirow[t]{3}{*}{0.224} \\
\hline Yes & 136 & 9.4 & 63 & 8.5 & 73 & 10.4 & \\
\hline Missing & 12 & & 5 & & 7 & & \\
\hline \multicolumn{8}{|l|}{ Gynaecological surgery² } \\
\hline No & 1143 & 78.7 & 578 & 79.7 & 565 & 79.7 & \multirow[t]{7}{*}{0.352} \\
\hline Yes & 310 & 21.3 & 166 & 22.3 & 144 & 20.3 & \\
\hline Sterilisation & 103 & 7.1 & 52 & & 51 & 7.2 & \\
\hline Oopherectomy & 33 & 2.3 & 21 & 2.8 & 12 & 1.7 & \\
\hline Hysterectomy & 82 & 5.6 & 40 & 5.4 & 42 & 5.9 & \\
\hline Total Hysterectomy/TAHBSO & 69 & 4.8 & 37 & & 32 & 4.5 & \\
\hline Salpingectomy/salpingostomy & 23 & 1.6 & 16 & 2.1 & 7 & & \\
\hline \multicolumn{8}{|l|}{ Body Mass Index (BMI) $)^{2}$} \\
\hline Underweight & 48 & 3.3 & 16 & & 32 & 4.5 & \multirow[t]{4}{*}{0.030} \\
\hline Normal weight & 812 & 55.9 & 425 & 57.1 & 387 & & \\
\hline Overweight & 576 & 39.6 & 292 & & 284 & 40.0 & \\
\hline Missing & 17 & & 11 & & 6 & & \\
\hline \multicolumn{8}{|l|}{ Diabetes status ${ }^{2}$} \\
\hline No & 1335 & 91.9 & 673 & 91.1 & 662 & 93.8 & \multirow[t]{3}{*}{0.050} \\
\hline Yes & 110 & 7.6 & 66 & 8.9 & 44 & 6.2 & \\
\hline Missing & 8 & & 5 & & 3 & & \\
\hline \multicolumn{8}{|l|}{ Smoking status ${ }^{2}$} \\
\hline Never & 1312 & 90.3 & 671 & 90.2 & 641 & 90.4 & \multirow[t]{2}{*}{0.887} \\
\hline Ever smoked & 141 & 9.7 & 73 & 9.8 & 68 & 9.6 & \\
\hline
\end{tabular}

Indicates variables in the Gail Model

${ }^{1}$ Indicates continuous variable

${ }^{2}$ Indicates categorical variable

T-test was used for continuous variables and chi-square test for categorical variables

Table 2 Summary for two-step cluster analysis

\begin{tabular}{llccc}
\hline Model & Exclusion $^{\text {a }}$ & Number of Clusters & Schwarz's Bayesian Criterion (BIC) & Cluster quality \\
\hline Full model & None & 4 & 18827.990 & Poor \\
Model 1 & Exclude smoking status & 2 & 18959.512 & Fair \\
Model 2 & Exclude age at menarche & 5 & 16456.869 & Poor \\
Model 3 & Exclude oral contraceptive status & 2 & 16212.759 & Fair \\
Model 4 & Exclude Gynaecology surgery status & 2 & 15089.163 & Fair \\
Model 5 & Exclude ethnicity & 3 & 12973.058 & Fair \\
Model 6 & Exclude parity status & 2 & 13416.631 & Fair \\
Model 7 & Exclude menopausal status include parity & 3 & 13372.869 & Fair \\
Model 8 & Exclude menopausal status & 3 & 13453.375 & Fair \\
\hline Full
\end{tabular}

${ }^{\mathrm{a}}$ Full model consists of all variables in Table 1, mammography history, age at first screening and motivators for attending screening. Model 1 - Model 8 : sequentially excluding variables with least association with mammography history 
Table 3 Groups of asymptomatic healthy women attending Malaysian Mammographic study using the cluster analysis ( $N=989$ )

\begin{tabular}{|c|c|c|c|c|c|c|c|}
\hline & Cluster & & Cluster & & Cluster & & $P$-value \\
\hline & $N=451$ & & $N=262$ & & $N=276$ & & \\
\hline & Mean & $\mathrm{sd}$ & Mean & $\mathrm{sd}$ & Mean & $\mathrm{sd}$ & \\
\hline Age $\left(\right.$ years) ${ }^{a}$ & 52 & 6.0 & 45 & 5.0 & 51 & 8.0 & $<0.001$ \\
\hline Age at first mammogram (years) ${ }^{a}$ & 44 & 6.0 & 45 & 5.0 & 50 & 7.0 & $<0.001$ \\
\hline Age at first live birth (years) ${ }^{a}$ & 28 & 4.0 & 29 & 4.0 & 25 & 5.0 & $<0.001$ \\
\hline & N & $\%$ & $\mathrm{~N}$ & $\%$ & N & $\%$ & \\
\hline Previous mammogram status ${ }^{b}$ & & & & & & & \\
\hline Never had a mammogram before & 0 & 0.0 & 258 & 98.5 & 259 & 93.8 & $<0.001$ \\
\hline Have had a mammogram before & 451 & 100.0 & 4 & 1.5 & 17 & 6.2 & \\
\hline Education level $^{b}$ & & & & & & & \\
\hline Primary & 9 & 2.0 & 0 & 0.0 & 54 & 19.6 & $<0.001$ \\
\hline Secondary & 222 & 49.2 & 66 & 25.2 & 219 & 79.3 & \\
\hline Tertiary & 220 & 48.8 & 196 & 74.8 & 3 & 1.1 & \\
\hline Monthly income $(\mathrm{RM})^{\mathrm{b}}$ & & & & & & & \\
\hline Below 5 k & 180 & 39.9 & 36 & 13.7 & 236 & 85.5 & $<0.001$ \\
\hline $5 \mathrm{k}$ to $10 \mathrm{k}$ & 164 & 36.4 & 127 & 48.5 & 37 & 13.4 & \\
\hline Above $10 \mathrm{k}$ & 107 & 23.7 & 99 & 37.8 & 3 & 1.1 & \\
\hline Family history of breast cancer ${ }^{b}$ & & & & & & & \\
\hline None & 392 & 86.9 & 237 & 90.5 & 261 & 94.6 & 0.009 \\
\hline 1 affected individuals & 54 & 12.0 & 25 & 9.5 & 14 & 5.1 & \\
\hline 2 affected individuals & 5 & 1.1 & 0 & 0.0 & 1 & 0.4 & \\
\hline HRT Usage ${ }^{b}$ & & & & & & & \\
\hline Never & 384 & 85.1 & 255 & 97.3 & 259 & 93.8 & $<0.001$ \\
\hline Ever used & 67 & 14.9 & 7 & 2.7 & 17 & 6.2 & \\
\hline $\mathrm{BMI}^{\mathrm{b}}$ & & & & & & & \\
\hline Underweight & 8 & 1.8 & 6 & 2.3 & 6 & 2.2 & 0.001 \\
\hline Normal weight & 264 & 58.5 & 162 & 61.8 & 126 & 45.7 & \\
\hline Overweight & 179 & 39.7 & 94 & 35.9 & 144 & 52.2 & \\
\hline Diabetes status ${ }^{b}$ & & & & & & & \\
\hline Unaffected & 420 & 93.1 & 255 & 97.3 & 235 & 85.1 & $<0.001$ \\
\hline Affected & 31 & 6.9 & 7 & 2.7 & 41 & 14.9 & \\
\hline Motivators for first mammogram ${ }^{b}$ & & & & & & & \\
\hline Family \& Friends & 147 & 32.6 & 52 & 19.8 & 25 & 9.1 & $<0.001$ \\
\hline Doctor & 92 & 20.4 & 75 & 28.6 & 119 & 43.1 & \\
\hline Myself & 67 & 14.9 & 16 & 6.1 & 23 & 8.3 & \\
\hline Public campaign & 60 & 13.3 & 34 & 13.0 & 14 & 5.1 & \\
\hline More than 1 motivators & 37 & 8.2 & 23 & 8.8 & 17 & 6.2 & \\
\hline No motivators & 48 & 10.6 & 62 & 23.7 & 78 & 28.3 & \\
\hline
\end{tabular}

Indicates continuous variable

${ }^{\mathrm{b}}$ Indicates categorical variable

primary or secondary level, and $85.5 \%$ reported a monthly income of lower than RM5,000. Women from this cluster had their first live birth at the youngest age ( 25 years), had the least significant family history of breast cancer, and the largest proportion of diabetic (14.9\%) and overweight women (52.2\%). Significantly, amongst these older women from a lower socio-economic group, the majority were motivated by their doctors to attend opportunistic screening. 
Although ethnicity was excluded from cluster analysis, further examination indicated that cluster 1 had the highest proportion among Indian women (70 out of 223, $31 \%)$ and cluster 2 the highest among Malay women (76 out of $160,44 \%$ ).

\section{Discussion}

The incidence of breast cancer is rising in most parts of Asia and Asian governments, particularly those from low and middle-income countries, face significant challenges in providing cost-effective and equitable screening for breast cancer. To date, the majority of low and middle-income Asian countries only offer opportunistic screening and the aspiration is that through health education and community health programmes, awareness and uptake of screening can help to ensure earlier presentation. In this study, we show that the majority of women attending opportunistic screening have an estimated $<2 \%$ risk of breast cancer in the next ten years, a threshold which is often considered where the benefits of screening outweigh the potential harms of overdiagnosis. This suggests that opportunistic screening in a private hospital in Malaysia does not target the women at high risk of breast cancer.

Previous studies using logistic regression have demonstrated a number of variables are associated with participation in mammography screening, but these studies provide limited information on how to target different groups of women $[17,18,22]$. In our study, we applied a different analytical method and suggest that functional clustering has provided insight into how screening messages should be framed for more effective promotion of mammography screening in the future. First, women with a higher risk of breast cancer on the basis of family history of breast cancer were more likely to attend screening at a younger age and they were motivated to participate in screening by various avenues. This suggests that health education focusing on the familial risk of breast cancer could be a strong motivator for Asian women to participate in screening but this approach has not hitherto been explored. Second, highly educated women could be motivated through a number of avenues including by their doctors, by family and friends or by public campaigns. Third, women in lower socioeconomic classes were more likely to be motivated by their doctors to participate in screening. Taken together, this suggests that whilst highly educated women were accessible through public campaigns, women in lower socio-economic classes may not respond similarly to such campaigns. This is consistent with a systematic review of interventions to increase uptake of screening mammography among Asian women which suggests that media campaigns alone may be ineffective in increasing screening uptake [9]. In addition, our data suggests that doctors remain a significant avenue for educating women in lower socio-economic groups about screening and health education should specifically encourage primary care physicians to educate their clients about the potential benefits of screening. This is consistent with studies in Indian, Pakistani and Bangladeshi women in the UK where cultural awareness training for healthcare workers was found to increase mammography uptake [23].

The strength of the MyMammo study is the relatively large sample size and availability of data on breast cancer risk factors, which in turns enable the determination of the estimated risk of breast cancer. To date, reports on barriers and motivators among developing Asian countries have been limited to small cohorts, with limited information about breast cancer risk factors. However, the MyMammo study has a number of limitations. First, the study is conducted in a private hospital and study participants were asked to contribute a blood sample for research to determine genetic determinants of mammographic density. It is unknown whether these would have affected participation levels and the profiles of participating women. Second, as this is an opportunistic screening program, findings from this study cannot be extrapolated to the general population as it only represents a subset of women that came forward for screening.

\section{Conclusions}

The MyMammo Study has shown that the avenues for women to become aware of and be motivated to participate in opportunistic screening is different in high-income and low socio-economic women. Findings from this study may have implications on the approach of future health education and community awareness programmes in Malaysia and other Asian countries.

\section{Competing interests}

The author(s) declare that they have no competing interests.

\section{Authors' contributions}

$\mathrm{NH}$ and WKH carried out the statistical analysis and drafted the manuscript. $\mathrm{SM}$ recruited the patients and contributed to the design and coordination of the study. ST conceived the study, contributed to the design and coordination and drafted the manuscript. All authors read and approved the final manuscript.

\section{Acknowledgements}

We thank Dr Yip Cheng Har and Maheswari Jaganathan for assistance with the recruitment of women in the study, and Sime Darby Ladies Professional Golf Association (LPGA) for funding the subsidized mammography programme. Sime Darby LPGA were not involved in the design, collection, analysis or interpretation of results.

\section{Author details}

${ }^{1}$ Cancer Research Initiatives Foundation, Sime Darby Medical Centre, 1 Jalan SS12/1A, Subang Jaya 47500, Selangor, Malaysia. ${ }^{2}$ Breast Cancer Research Unit, University Malaya Cancer Research Institute, Faculty of Medicine, University Malaya Medical Centre, University Malaya, 50603 Kuala Lumpur, Malaysia. ${ }^{3}$ Department of Applied Mathematics, Faculty of Engineering, University of Nottingham Malaysia Campus, Jalan Broga, 43500 Semenyih, Selangor, Malaysia. 
Received: 18 December 2014 Accepted: 29 May 2015

Published online: 12 June 2015

\section{References}

1. Ferlay J, Shin HR, Bray F, Forman D, Mathers C, Parkin DM. Estimates of worldwide burden of cancer in 2008: GLOBOCAN 2008. Int J Cancer. 2010;127(12):2893-917.

2. Katanoda K, Matsuda T, Matsuda A, Shibata A, Nishino Y, Fujita M, et al. An updated report of the trends in cancer incidence and mortality in Japan. Jpn J Clin Oncol. 2013;43(5):492-507.

3. Seow A, Duffy SW, McGee MA, Lee J, Lee HP. Breast cancer in Singapore: trends in incidence 1968-1992. Int J Epidemiol. 1996;25(1):40-5.

4. Chia KS. Cancer survival in Singapore, 1993-1997. IARC Sci Publ. 2011;2(162):183-98.

5. Lan NH, Laohasiriwong W, Stewart JF. Survival probability and prognostic factors for breast cancer patients in Vietnam. Global Health Action. 2013;6:1-9.

6. Lee JH, Yim SH, Won YJ, Jung KW, Son BH, Lee HD, et al. Population-based breast cancer statistics in Korea during 1993-2002: incidence, mortality, and survival. J Korean Med Sci. 2007;22(Suppl):S11-16.

7. Leong SP, Shen ZZ, Liu TJ, Agarwal G, Tajima T, Paik NS, et al. Is breast cancer the same disease in Asian and Western countries? World J Surg. 2010;34(10):2308-24.

8. Corbex M, Burton R, Sancho-Garnier H. Breast cancer early detection methods for low and middle income countries, a review of the evidence. Breast. 2012;21(4):428-34.

9. Lu M, Moritz S, Lorenzetti D, Sykes L, Straus S, Quan H. A systematic review of interventions to increase breast and cervical cancer screening uptake among Asian women. BMC Public Health. 2012;12:413.

10. Sim HL, Seah M, Tan SM. Breast cancer knowledge and screening practices: a survey of 1,000 Asian women. Singapore Med J. 2009;50(2):132-8.

11. Lee K, Lim HT, Park SM. Factors associated with use of breast cancer screening services by women aged $>$ or $=40$ years in Korea: the third Korea National Health and Nutrition Examination Survey 2005 (KNHANES III). BMC Cancer. 2010;10:144.

12. Ishikawa Y, Hirai K, Saito H, Fukuyoshi J, Yonekura A, Harada K, et al. Costeffectiveness of a tailored intervention designed to increase breast cancer screening among a non-adherent population: a randomized controlled trial. BMC Public Health. 2012;12:760.

13. Yoo KB, Kwon JA, Cho E, Kang MH, Nam JM, Choi KS, et al. Is mammography for breast cancer screening cost-effective in both Western and asian countries? results of a systematic review. Asian Pac J Cancer Prev. 2013;14(7):4141-9.

14. Amranand NN S, Nesterenko I, Rankova A, Tam K, Tangkijngamvong N. Promoting awareness and early detection of breast cancer in Thailand. 2010.

15. Rosmawati NH. The usage and knowledge of mammography among women in sub-urban area in Terengganu, Malaysia. Asian Pac J Cancer Prev. 2010;11(3):767-71.

16. Dahlui M, Gan DE, Taib NA, Lim JN. Breast screening and health issues among rural females in Malaysia: how much do they know and practice? Prev Med. 2013;57(Suppl):S18-20.

17. Parsa P, Kandiah M. Predictors of adherence to clinical breast examination and mammography screening among Malaysian women. Asian Pac J Cancer Prev. 2010;11(3):681-8.

18. Teo CT, Yeo YW, Lee SC. Screening mammography behavior and barriers in Singaporean Asian women. Am J Health Behav. 2013;37(5):667-82.

19. Al-Naggar RA, Bobryshev Y. Practice and barriers of mammography among Malaysian women in the general population. Asian Pac J Cancer Prev. 2012;13(8):3595-600

20. Lamyian M, Hydarnia A, Ahmadi F, Faghihzadeh S, Aguilar-Vafaie ME. Barriers to and factors facilitating breast cancer screening among Iranian women: a qualitative study. East Mediterr Health J. 2007;13(5):1160-9.

21. Matsuno RK, Costantino JP, Ziegler RG, Anderson GL, Li H, Pee D, et al. Projecting individualized absolute invasive breast cancer risk in Asian and Pacific Islander American women. J Natl Cancer Inst. 2011;103(12):951-61.

22. Lerman C, Rimer B, Trock B, Balshem A, Engstrom PF. Factors associated with repeat adherence to breast cancer screening. Prev Med. 1990;19(3):279-90.

23. Atri J, Falshaw M, Gregg R, Robson J, Omar RZ, Dixon S. Improving uptake of breast screening in multiethnic populations: a randomised controlled trial using practice reception staff to contact non-attenders. BMJ (Clinical research ed). 1997;315(7119):1356-9.

\section{Submit your next manuscript to BioMed Central and take full advantage of:}

- Convenient online submission

- Thorough peer review

- No space constraints or color figure charges

- Immediate publication on acceptance

- Inclusion in PubMed, CAS, Scopus and Google Scholar

- Research which is freely available for redistribution

Submit your manuscript at www.biomedcentral.com/submit 